\title{
TUNNELING TRANSPARENCY OF THE GRAPHENE SYMMETRICAL DOUBLE-BARRIER STRUCTURE WITH THE FERMI VELOCITY BARRIERS
}

\author{
A. Korol, S. Litvynchuk, I. Hutsalo, V. Vyshniak \\ National University of Food Technologies
}

\begin{tabular}{|c|c|}
\hline Key words: & ABSTRACT \\
\hline $\begin{array}{l}\text { Grapheme } \\
\text { Nanostructures } \\
\text { Fermi velocity } \\
\text { Dirac-Weyl equation } \\
\text { Transmission coefficient }\end{array}$ & $\begin{array}{l}\text { The motion of the relativistic Dirac-Weyl quasi-electrons is } \\
\text { considered in the system that is the double-barrier tunneling- } \\
\text { resonant structure with the symmetrical rectangular Fermi } \\
\text { velocity barriers. The rates of the transmission of the quasi- } \\
\text { electrons in this structure is calculated within a continuum }\end{array}$ \\
\hline $\begin{array}{l}\quad \text { Article history: } \\
\text { Received } 01.11 .2017 \\
\text { Received in revised form } \\
16.11 .2017 \\
\text { Accepted } 15.12 .2017\end{array}$ & $\begin{array}{l}\text { model by the transfer matrix method. Focus is made on the } \\
\text { analysis of the dependence of the quantum transparency of } \\
\text { this system on its geometrical parameters: the barrier } \\
\text { thickness d and the width of the quantum well w. It is shown } \\
\text { in particular that the transmission rate strongly depends on }\end{array}$ \\
\hline $\begin{array}{l}\text { Corresponding author: } \\
\text { V. Vyshniak } \\
\text { E-mail: } \\
\text { npnuht@ukr.net }\end{array}$ & $\begin{array}{l}\text { these quantities and this allows to regulate flexibly the } \\
\text { energy specter of the systemwhich is considered. }\end{array}$ \\
\hline
\end{tabular}

DOI: $10.24263 / 2225-2924-2017-23-6-15$

\section{ТУНЕЛЬНА ПРОЗОРІСТЬ ГРАФЕНОВОЇ СИМЕТРИЧНОЇ ДВОБАР'ЄРНОЇ СТРУКТУРИ 3 БАР'ЄРАМИ ШВИДКОСТІ ФЕРМІ}

\author{
А.М. Король, С.І. Літвинчук, І.В. Гуцало, В.В. Вишняк \\ Національний університет харчових технологій
}

У статті розглянуто рух релятивістських квазіелектронів Дірака-Вейля в системі, що являс собою двобар 'єрну тунельно-резонансну структуру із симетричними прямокутними бар'єрами швидкості Фермі. Коефіцієнт трансмісії квазіелектронів у даній структурі розраховано в континуальній моделі методом трансферних матриць. Наголос зроблено на аналізі залежності квантової прозорості системи від ї̈ геометричних параметрів: товщини бар'єрів d i ширини квантової ями w. Показано, зокрема, що коефіцієнт трансмісії сильно залежить від величин $d i w$, що дає змогу гнучко регулювати енергетичний спектр системи, щяо розглядається.

Ключові слова: графен, наноструктури,швидкість Фермі, рівняння ДіракаВейля, коефіиієнт трансмісії. 
Постановка проблеми. Останніми роками велика увага дослідників прикута до вивчення різних структур на основі графену, що природно пояснюється його нетривіальними властивостями, в тому числі електронними.

Достатньо назвати аналогію $\pi$-електронів графену з безмасовими діраківськими ферміонами при низьких енергіях (що формально описуються безмасовим рівнянням Дірака), лінійний закон дисперсії, властивість кіральності, клейнівське тунелювання, високу рухливість, балістичний транспорт, незвичайний квантовий ефект Холла тощо [1-13]. Слід також мати на увазі, що графен $\epsilon$ перспективним матеріалом у сучасній електроніці з погляду заміни кремнієвої технології, розвиток якої підійшов до своєї межі, на графенову.

Аналіз останніх досліджень і публікацій. Балістичний транспорт квазіелектронів Дірака-Вейля крізь області графену з різними швидкостями Фермі (бар'єри швидкості) розглядався в [6-13]. Було виявлено ряд нових важливих закономірностей. Зокрема, показано, що трансмісія крізь бар'єр швидкості є сильно анізотропною, при нормальному падінні квазічастинок на бар'єр вона є ідеальною (аналог парадоксу Клейна), за умови $v_{F}>v_{0}\left(v_{F}, v_{0}-\right.$ швидкості Фермі в бар'єрі і в звичайному графені відповідно) існує критичний кут трансмісії (аналог кута Брюстера в оптиці) для безмасових діраківських електронів, спостерігаються сильні резонансні ефекти, сильний вплив магнітного поля на зв'язані стани тощо.

3 метою регулювання транспортних властивостей графенових структур використовуються різні методи та прийоми, зокрема вивчався вплив на динаміку квазіелектронів зовнішніх електричного та магнітного полів. Ці поля можуть створювати потенціальні бар'єри для носіїв заряду, а змінюючи величину бар'єрів, можна зручно регулювати поведінку електронів або дірок. Недавно було запропоновано ще один шлях для керування електронними властивостями графенових структур, а саме: за допомогою просторової зміни швидкості Фермі [6]. Було запропоновано декілька методів одержання структур, в яких швидкість Фермі квазічастинок є просторово залежною. Це досягнення технології відкриває нові можливості для створення наноелектронних приладів з бажаними транспортними властивостями. Але оскільки не всі властивості і характеристики зазначених структур вивчені і відомі, їх дослідження триває.

У попередньому дослідженні [5] ми розраховували й аналізували коефіцієнт трансмісії квазіелектронів Дірака-Вейля крізь однобар'єрну графенову структуру з різними швидкостями Фермі. Об'єктом даного дослідження $\epsilon$ двобар'єрна структура на основі графену. Слід відразу підкреслити, що процес квантового проникнення квазічастинок крізь двобар'єрну структуру істотним чином відрізняється від аналогічного процесу в однобар'єрній структурі. Це природним чином пов'язано з наявністю квантової ями в двобар'єрній структурі, що докорінно змінює умови тунелювання в ній.

Слід також підкреслити важливість двобар'єрної структури, пов'язану $з$ тим, що вона $є$ базовим елементом мультибар'єрних структур (надграток), які, як відомо, широко використовуються в сучасній наноелектроніці. Електронні процеси саме в двобар'єрній структурі обумовлюють і визначають квантову тунельну прозорість мультибар'єрних об’єктів. 
Водночас двобар'єрна структура може бути самодостатньою і навіть вигіднішою, ніж мультибар'єрні об'єкти, через їі менші розміри і більшу технологічність. Це твердження стосується, зокрема, важливої проблеми одержання негативного диференціального опору на основі механізму резонансного тунелювання.

Метою дослідження $\epsilon$ аналіз процесів резонансного тунелювання в графеновій двобар'єрній структурі, в якій бар'єри утворюються за рахунок областей 3 різними швидкостями Фермі.

Викладення основних результатів дослідження. Вважатимемо, що до прямокутних симетричних бар'єрних областей прикладено зовнішній електростатичний потенціал $U$ - так що фактично ми маємо справу із бар'єрами подвійної природи. Як відомо, за допомогою електростатичного потенціалу зручно регулювати транспорт носіїв заряду в бар'єрних системах, і далі буде видно, що справді наявність потенціалу $U$ істотно впливає на рух носіїв заряду в структурі, що розглядається.

Оскільки ми розглядаємо графен, в якому швидкості Фермі квазічастинок залежать від просторової координати $\vec{r}$, тобто $\vec{v}_{F}=\vec{v}_{F}(\vec{r})$, рух квазіелектронів підпорядковується такому безмасовому рівнянню Дірака-Вейля:

$$
i \hbar \vec{\sigma} \nabla[\sqrt{\vec{v}(\vec{r})} \phi(\vec{r})] \sqrt{\vec{v}(\vec{r})}=E \phi(\vec{r}),
$$

де $\vec{\sigma}=\left(\sigma_{x}, \sigma_{y}\right)-$ двовимірні матриці Паулі; $\phi(\vec{r})=\left[\phi_{A}(\vec{r}), \phi_{B}(\vec{r})\right]^{T}-$ двокомпонентний спінор; $T$ - символ транспонування. Вводячи допоміжний спінор $\varphi(r)=\sqrt{\vec{v}(\vec{r})} \phi(\vec{r})$, можна записати рівняння (1) у такій формі:

$$
-i \hbar \vec{v}(\vec{r}) \vec{\sigma} \nabla \varphi(\vec{r})=E \varphi(\vec{r}) .
$$

Припустимо, що зовнішній потенціал являє собою прямокутний бар'єр, розташований вздовж осі ОХ. Тоді із рівняння (2) можна одержати:

$$
\frac{d^{2} \varphi_{A, B}}{d x^{2}}+\left(k^{2}-k_{y}^{2}\right) \varphi_{A, B}=0,
$$

де $A, B$ відносяться до графенових підграток $A$ і $B$, квазіімпульс $k$ дорівнює $k=(E-U)$ поза бар'єром і $k=\frac{E-U}{v_{F}}$ всередині бар'єру, прийнято одиниці вимірювання $\hbar=v_{0}=1$, де $v_{\mathrm{o}}$ - швидкість Фермі в квантових ямах (у звичайному графені). Якщо представити розв'язок для власних функцій у вигляді плоских хвиль, що рухаються вздовж осі $0 x$ в прямому і зворотному напрямках, то одержимо:

$$
\phi(x)=\left[a^{i q x}\left(\begin{array}{c}
1 \\
g^{+}
\end{array}\right)+b^{-i q x}\left(\begin{array}{c}
1 \\
g^{-}
\end{array}\right)\right],
$$

де $q=\sqrt{k^{2}-k_{y}^{2}}$ для $k^{2}>k_{y}{ }^{2}, \mathrm{i} q=i \sqrt{k_{y}^{2}-k^{2}}$ для $k^{2}<k_{y}{ }^{2}, g_{-}^{+}=\frac{\left({ }_{-}^{+} q+i k_{y}\right) v_{F}}{E-U}$.

Верхній рядок в (4) стосується підгратки $A$, нижній $-B$. 
Використовуючи далі граничні умови у вигляді

$$
\sqrt{v_{F}} \phi\left(x_{b}^{-}\right)=\sqrt{v_{0}} \phi\left(x_{b}^{+}\right),
$$

де індекс $b$ відноситься до бар'єру, $x_{b}$ - координата межі: бар'єр - позабар'єрна область, можна знайти вираз для коефіцієнта трансмісії квазічастинок Дірака-Вейля крізь задану структуру.

В принципі для коефіцієнта трансмісії квазіелектронів крізь ДБТРС можна одержати аналітичну формулу, але оскільки вона є досить громіздкою, зручніше скористатися методом трансферних матриць. Матриця, яка в континуальній моделі переносить розв'язок через гетеромежі, має вигляд:

$$
\begin{gathered}
M_{j}=\frac{1}{\cos \theta_{j}}\left(\begin{array}{cc}
\cos \left(q_{j} \Delta x-\theta\right) & i \sin \left(q_{j} \Delta x\right) \\
i \sin \left(q_{j} \Delta x\right) & \cos \left(q_{j} \Delta x+\theta\right)
\end{array}\right), \\
\theta_{j}=\arg \sin \left(\frac{k_{y}}{k_{j}}\right),
\end{gathered}
$$

де індекс ј нумерує гетеромежі, величина $\Delta$ дельта $x$ - це відстань, на яку переноситься розв'язок. Коефіцієнт трансмісії $\mathrm{T}$ виражається через діагональні елементи матриці, що є добутком $\mathrm{n}$ матриць $M_{j}$, де $\mathrm{n}$ дорівнює загальній кількості гетеромеж [11-13].

Проведені нами розрахунки показують, що спектри трансмісії мають яскраво виражений тунельно-резонансний характер, тобто являють собою набір почергово змінних областей енергії із високими, близькими до одиниці значеннями коефіцієнта трансмісії, і областей із набагато меншими його значеннями. Крім того, важливо зазначити, що в загальному випадку, тобто для довільних $v_{F}$ спектри трансмісії є періодичними по енергії. Також важливо, що вони мають невпорядкований, хаотичний характер. Однак відомо, що одна з унікальних особливостей графену полягає в тому, що він може виявляти абсолютно оригінальні властивості для деяких ексклюзивних значень параметрів структур на його основі. Цей факт підтверджується і для проблеми, що розглядається у пропонованій статті.

Наведені далі рис. 1, 2, на яких зображено залежність коефіціснта трансмісії Т(Е) квазіелектронів крізь ДБТРС з бар'єрами швидкості Фермі, показують, що, по-перше, спектри трансмісії можуть представляти дуже розмаїту конфігурацію дозволених (заборонених) енергетичних зон; по-друге, досліджувані спектри сильно залежать від геометричних параметрів розглядуваної структури, а саме: від товщин бар'єрів швидкості Фермі і ширини квантових ям.

Зупинимось спочатку на залежності спектрів трансмісії від ширини квантової ями $w$. Тут прослідковується певна однозначна тенденція зміни спектрів із зростанням величини $w$. Відзначимо такі найважливіші риси цих змін:

1. Для певних обраних значень співвідношення параметрів $d$ i $w$ період спектрів залишається незмінним, зокрема, для параметрів рис. $1-$ період дорівнює $2 \pi$.

2. Конфігурація дозволених і заборонених зон із зростанням величини $\frac{W}{d}$ зберігається. 
3. Кількість резонансів (зон пропускання) із збільшенням $w$ (коли $w$ дорівнює цілому числу) зростає рівно у $2 w$ разів. Очевидно, що щілини при цьому стають вужчими.

4. Щілини кожного даного спектра мають приблизно однакову ширину. При цьому найширші щілини розміщені в околі середини періоду, а в міру віддалення від середини щілини вужчають.

У тому разі, коли відношення $\frac{w}{d}$ не дорівнює цілому числу, спектри мають складний і несиметричний характер.

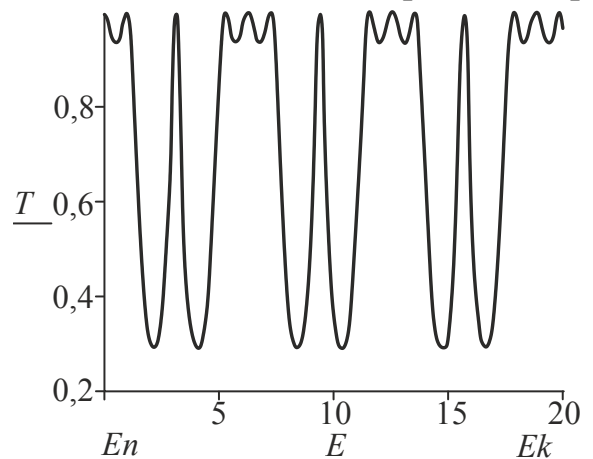

a

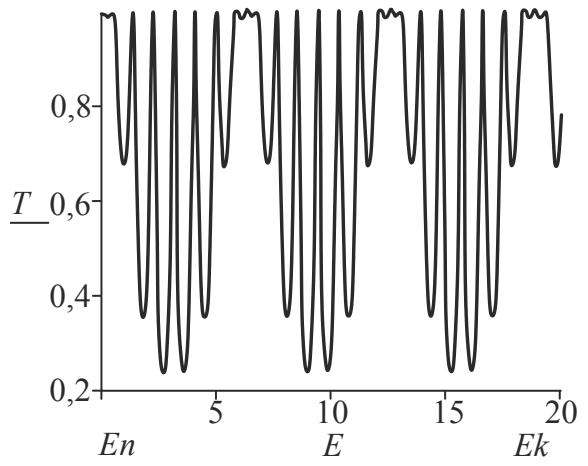

B

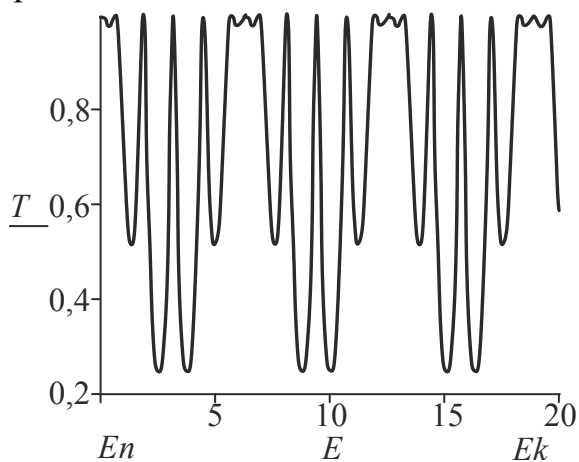

б

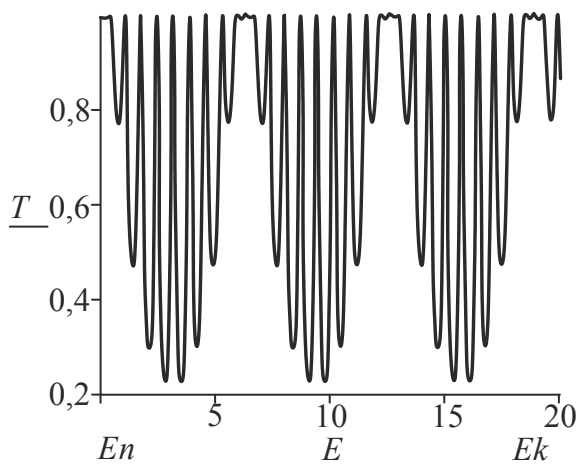

$\Gamma$

Рис. 1. Залежність коефіцієнта трансмісії квазіелектронів Дірака-Вейля крізь двобар'єрну тунельно-резонансну структуру із прямокутними бар'єрами швидкості Фермі. Значення параметрів: для всіх чотирьох рисунків $v_{F}=2$ (для обох бар'срів); товщина обох бар'єрів однакова $d=1$; значення ширини квантової ями $w=1,2,3,4$ для рисунків а, б, в, г відповідно

Залежність спектрів трансмісії від товщини бар'єрів $d$ не можна описати такою простою схемою, як для випадку зміни величини ширини квантової ями $w$ - навіть для спеціально обраних значень $d$ i $w$. Із зростанням $d$ спостерігається згущення резонансних ліній, що, до речі, є особливістю, притаманною саме графеновим бар'єрним структурам. Але на відміну від попередньо розглянутого випадку зміни $w$, в даному разі (зміни $d$ ) для кожного значення $\frac{w}{d}$ утворюється своя індивідуальна конфігурація енергетичних 
зон. При цьому для обраних значень параметрів, для яких спектри є регулярними і симетричними по енергії, період може бути рівний як $2 \pi$, так i $\pi$. Так, у разі, коли $w=1$ для парних $d$ дорівнює $\pi$, а для непарних $-2 \pi$; при цьому кількість зон для парних $d$ дорівнює $d / 2$, а для непарних $d+1$.

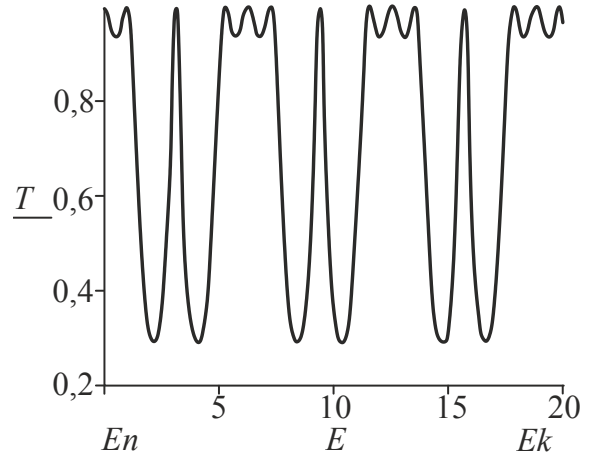

a

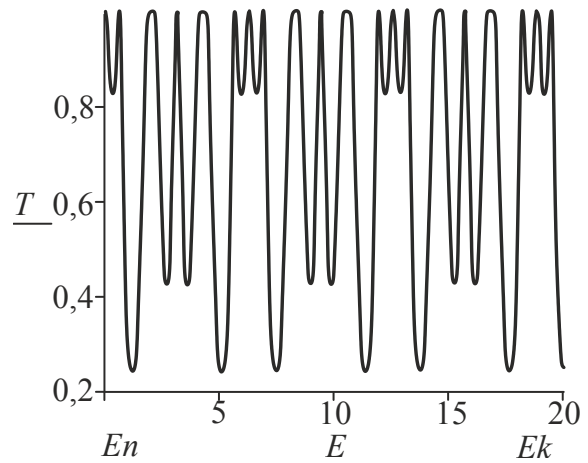

B

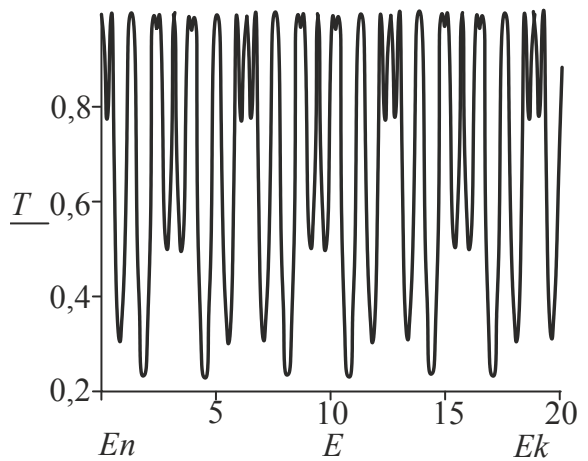

д

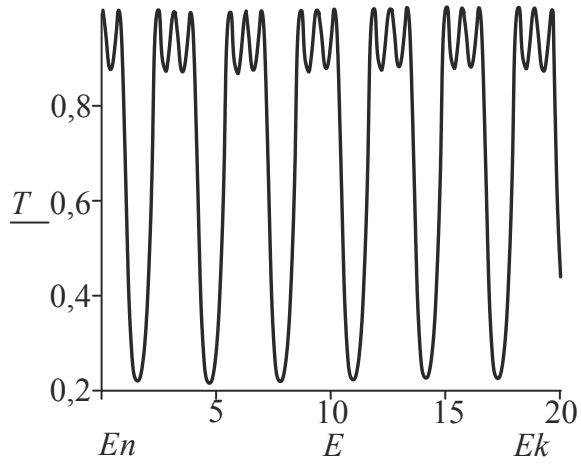

6

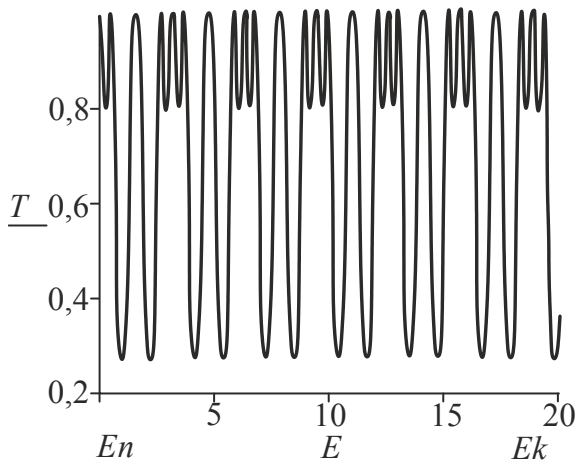

Г

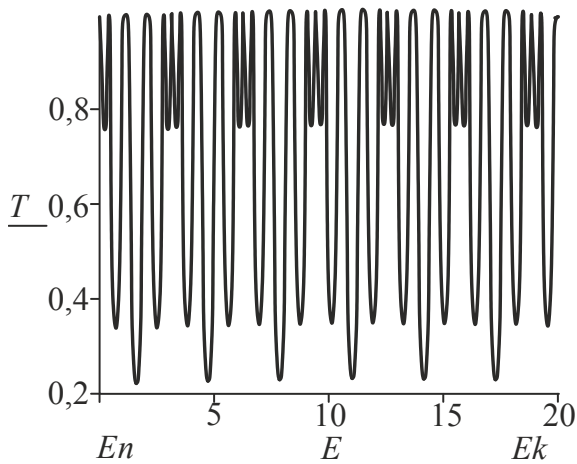

e

Рис. 2. Залежність коефіцієнта трансмісії квазіелектронів Дірака-Вейля крізь розглядувану двобар'срну тунельно-резонансну структуру із прямокутними

бар'срами швидкості Фермі. Значення параметрів: для всіх рисунків $v_{F}=2$ (для обох бар'єрів); значення ширини квантової ями однакове $w=1$; товщина обох бар'єрів однакова і для рисунків а, б, в, г, д, е дорівнює 1, 2, 3, 4, 5, 6 відповідно 


\section{Висновки}

Розраховано і проаналізовано коефіцієнт квантової трансмісії квазіелектронів Дірака-Вейля крізь два симетричні бар'єри із квантовою ямою посередині. Бар'єри утворюються за рахунок різних швидкостей Фермі в різних областях структури і є прямокутними. Показано, що спектри трансмісії мають яскраво виражений тунельно-резонансний характер. Важливою рисою спектрів $\epsilon$ те, що вони періодичні по всій шкалі енергій. Конфігурація дозволених і заборонених зон істотно залежить від значень швидкості Фермі в бар'єрах, а також від товщини бар'єрів і ширини квантової ями. Із цього випливає, що дана структура може ефективно слугувати енергетичним фільтром для квазіелектронів Дірака-Вейля, за допомогою якого зручно регулювати діапазон енергій для фільтрації носіїв заряду.

\section{Література}

1. Geim A.K., Novoselov K.S. The rise of graphene // Nat. Materials. - 2007. — Vol. 6. P. $183-188$.

2. Castro Neto A. N., Guinea F., Peres N. M. R., Novoselov K.S., Geim A.K. The electronic properties of graphene // Rev. Mod. Phys. - 2009. - Vol. 81. — P. 109-121.

3. Pereira J.M., Peeters F.M., Chaves A., Barbier M., Vasilopoulos P. Klein tunneling in single and multiple barriers in graphene // Semicond. Science Technology. — 2010 . - Vol. 25. P. $033002-033009$.

4. Cheianov V.V., Falko V.I. Selective transmission of Dirac electrons and ballistic magnetoresistance of n-p junctions in graphene // Phys. Rev. B. - 2006. — Vol. 74. — P. 041403041408.

5. Король А.М. Вплив швидкості Фермі на коефіцієнт трансмісії квазіелектронів Дірака-Вейля в однобар'єрній графеновій структурі / А.М. Король, В.В. Вишняк, С.І. Літвинчук, І.В. Гуцало // Наукові праці національного університету харчових технологій. - Т. 22, № 3. - C.183-190.

6. Raoux A., Polini M., Asgari R., Hamilton A.R., Fazio R., MacDonald A.H. Velocitymodulation control of electron-wave propagation in graphene // Phys. Rev. B. - 2010. - Vol. 81. - P. 073407-073412.

7. Krstajic P.M., Vasilopoulos P. Ballistic transport through graphene nanostructures of velocity and potential barriers // J. Phys.: Condens. Matter. — 2011. — Vol. 23. — P. 135302135312.

8. Lei Liu, Yu-Xian Li, Jian-Jun Liu. Transport properties of Dirac electrons in graphene based double velocity-barrier structures in electric and magnetic fields // Physics Letters A. 2012. - Vol. 376. - P. 3342-3350.

9. Concha A., Tesanovic Z. Effect of a velocity barrier on the ballistic transport of Dirac fermions // Phys. Rev. B. - 2010. — Vol. 82. - P. 033413-033418.

10. Wang Y., Liu Y., Wang B. Resonant tunnelling and enhanced Goos-Hänchen shift in graphene double velocity barrier structure // Physica E. - 2013. - Vol. 53. - P. 186-192.

11. Zhao P., Chen $X$. Electronic band gap and transport in Fibonacci quasi-periodic graphene superlattice // Appl. Phys. Lett. — 2011. — Vol. 99. - P. 182108 - 182113.

12. Korol A.M., Medvid N.V., Litvynchuk S.I. Transport properties of the Dirac-Weyl electrons through the graphene-based superlattice modulated by the Fermi velocity barrier // Springer Proceedings in Physics. - 2015. - Vol. 167. — P. 215-221.

13. Korol A.M., Litvynchuk S.I., Bagliuk S.V., Isai V.M. Energy spectra of the graphenebased Fibonacci superlattice modulated by the Fermi velocity barrier // Physical Science International Journal. — 2016. - Vol. 9(3). - P. 1-8. 